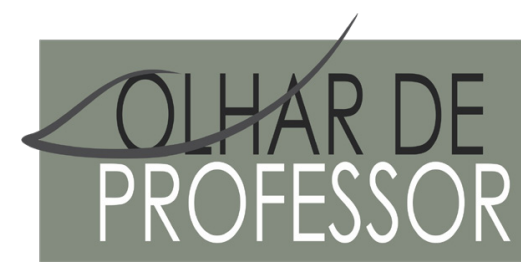

DOI: 10.5212/OLHARPROFR.v.22.0015

\title{
O ESTÁGIO SUPERVISIONADO EM EDUCAÇ̃̃o INFANTLL: ANÁLISE DE UM ROTEIRO DIDÁTICO PARA A ETAPA DE ATUAÇÃO
}

\author{
THE SUPERVISED INTERNSHIP IN CHILDHOOD EDUCATION: ANALYSIS OF A DIDACTIC SCRIPT FOR THE \\ ACTING STAGE
}

\section{LAS PRÁCTICAS DOCENTES SUPERVISADAS EN EDUCACIÓN INFANTIL: ANÁLISIS DE UN GUION DIDÁCTICO PARA LA ETAPA DE APLICACIÓN}

\author{
SANDRA REGINA GARDACHO PIETROBON* \\ RAYANE REGINA SCHEIDT GASPAREL ${ }^{* *}$ \\ ANTONIO CARLOS FRASSON ${ }^{\text {t*x+ }}$
}

\begin{abstract}
Resumo: O presente trabalho tem como objetivo apresentar a análise de um roteiro didático (PIETROBON, 2018) para a organização do planejamento na etapa da atuação no estágio supervisionado em Educação Infantil, no curso de Pedagogia da Universidade Estadual do Centro-Oeste, Campus Prudentópolis-PR. Após a finalização da etapa de atuação, uma pesquisa de levantamento foi realizada em uma abordagem qualitativa, com 22 acadêmicas. Elas avaliaram que o roteiro didático utilizado corresponde às necessidades das instituições e das crianças, não sugerindo nenhuma alteração quanto ao referido roteiro. Constatamos então que, embora o roteiro didático tenha sido elaborado para cursos de Pedagogia a distância no Estágio Supervisionado em Educação Infantil, também pode ser trabalhado em cursos de Pedagogia presenciais.
\end{abstract}

Palavras-chave: Estágio supervisionado. Educação infantil. Roteiro didático.

\begin{abstract}
This work aims presenting an analysis of a didactic script (PIETROBON, 2018) to organize the planning in the acting stage of the Supervised Internship in Childhood Education, at the Pedagogy faculty of the Universidade Estadual do Centro-Oeste, Campus Prudentópolis-PR. After finishing the acting stage, a survey was performed in a qualitative approach with 22 students. They evaluated that the didactic script used, corresponds to the needs from the institutions and the children, and they did not suggest any changes regarding the document mentioned. We noticed out that despite the didactic script has been elaborated for online learning Pedagogy courses, for its supervised internship in childhood education, it also might be used in Pedagogy traditional classes.
\end{abstract}

Keywords: Supervised internship. Childhood education. Didactic script.

Resumen: Este trabajo tiene el objetivo de presentar el análisis de un guion didáctico (PIETROBON, 2018) para organización del planeamiento en la etapa de actuación en la pasantía supervisada en Educación Infantil, en el curso de Pedagogía de la Universidad Estadual del Centro Oeste, Campus Prudentópolis-PR. Después de la finalización de la etapa de actuación, una encuesta de abordaje cualitativa fue realizada con 22 académicas. Ellas han evaluado que el guion didáctico utilizado corresponde a las necesidades de las instituciones y de los niños, y

\footnotetext{
* Doutora em Ensino pela Universidade Tecnológica Federal do Paraná (UTFPR). Docente do Departamento de Pedagogia da UNICENTRO, Campus Irati.spietrobom@unicentro.br

** Mestre em Educação (UNICENTRO). Doutoranda em Educação (UNICAMP). Docente do curso de Pedagogia da Universidade Estadual do Centro-Oeste, Campus Irati-PR. rayanegasparelo.0706@gmail.com

*** Mestre e Doutor em Educação(UNIMEP). Docente do Programa de Pós-graduação em Ensino de Ciência e Tecnologia (UTFPR). Líder do grupo de pesquisa: “Educação a distância: Formação docente para o ensino de Ciência e Tecnologia”(CNPQ/ UTFPR).ancafra@gmail.com
} 
no hubo sugerencias de cambio para el referido guion. Entonces fue constatado que, aunque el guion tenga sido desarrollado para cursos de Pedagogía a distancia, en la pasantía supervisada en Educación Infantil, también puede ser utilizado en cursos de Pedagogía presencial.

Palabras-clave: Pasantía. Educación infantil. Itinerario didáctico.

\section{INTRODUÇ̄̃̃O}

A discussão sobre ações e práticas no estágio supervisionado em cursos de formação docente traz elementos que podem servir de base para a construção de saberes experienciais, construídos na prática profissional. O estágio supervisionado profissionaliza e, como coloca Pineda (2015), garante a união entre teoria e prática na formação docente.

Neste trabalho enfoca-se o estágio supervisionado em Educação Infantil, no qual encontram-se reflexões acerca da prática pedagógica com crianças pequenas, que possuem sua particularidade, e a docência com elas envolve pensar, primeiramente, sobre o conceito de criança que os acadêmicos possuem.

Compreende-se a formação docente como locus que possibilita aprendizado e discussão sobre diferentes temáticas ligadas ao campo profissional, englobando saberes e conhecimentos que são base para que os futuros professores possam fazer suas escolhas teóricas, metodológicas e didáticas, o que não é distinto na Educação Infantil.

A prática pedagógica na etapa da Educação Infantil, no âmbito do estágio supervisionado, exige dos professores do curso de Pedagogia a realização de leituras sistemáticas, análise de pesquisas que traduzam práticas com crianças pequenas, bem como que organizem todas as etapas concernentes aos processos do estágio nas instituições que abrigam os acadêmicos nesse momento de profissionalização, contemplando etapa de observação, etapa de participação, e etapa de atuação ${ }^{1}$.

Assim, tem como problematização: O roteiro didático organizado por Pietrobon (2018), para a organização da prática pedagógica na Educação Infantil no estágio supervisionado em cursos de Pedagogia a distância atende às expectativas e necessidades de acadêmicos de um curso de Pedagogia presencial para a atuação na Educação Infantil? O objetivo, então, é apresentar análise de um roteiro didático para a organização do planejamento na etapa da atuação, no estágio supervisionado em Educação Infantil, com base no produto educacional de Pietrobon (2018).

O levantamento realizado demonstrou que há possibilidade da utilização do roteiro didático para o planejamento na Educação Infantil, considerando que as acadêmicas investigadas o utilizaram em seus planejamentos na etapa de atuação para o estágio supervisionado em Educação Infantil no primeiro semestre de 2019.

\section{A FORMAÇ̃̃O DOCENTE PARA A EDUCAÇ̃̃O INFANTIL NO CURSO DE PEDAGOGIA}

A Educação Infantil é uma das áreas formativas do curso de Pedagogia, conforme preveem as Diretrizes Curriculares Nacionais para a Graduação em Pedagogia (2006, p. 1):

Art. $2^{\circ}$ As Diretrizes Curriculares para o curso de Pedagogia aplicam-se à formação inicial para o exercício da docência na Educação Infantil e nos anos iniciais do Ensino Fundamental, nos cursos de Ensino Médio, na modalidade Normal, e em cursos de Educação Profissional na área de serviços e apoio escolar, bem como em outras áreas nas quais sejam previstos conhecimentos pedagógicos.

O curso de Pedagogia contempla, em sua proposta, conforme a regulamentação legal, disciplinas e atividades que dão suporte ao professor da Educação Infantil, nos aspectos teóricos e práticos da docência nesta etapa educativa, por meio de disciplinas que compõem o currículo do curso, bem como o estágio

\footnotetext{
${ }^{1}$ Indicam-se estas três etapas considerando o curso no qual foi realizada a análise descrita quanto ao roteiro didático para a organização do planejamento na Educação Infantil.
} 
supervisionado, que tem o objetivo de profissionalizar o futuro professor. Isto decorre de conquistas históricas e legais de que, para atuar na Educação Infantil, o profissional necessita de uma formação mínima, a qual está estabelecida pela Lei de Diretrizes e Bases da Educação Nacional - Lei nº 9.394/1996²:

Art. 62 A formação de docentes para atuar na educação básica far-se-á em nível superior, em curso de licenciatura, de graduação plena, em universidades e institutos superiores de educação, admitida, como formação mínima para o exercício do magistério na educação infantil e nos 5 (cinco) primeiros anos do ensino fundamental, a oferecida em nível médio na modalidade normal (BRASIL, 1996).

Com a obrigatoriedade de uma formação específica para a atuação na Educação Infantil, as Secretarias Municipais de Educação tiveram que se adequar em termos de contratação de pessoal e efetivação de concursos públicos, tomando em conta essa necessidade legal já preconizada desde a década de 1990. Contudo, ainda há aspectos a serem repensados na formação docente, quanto ao trabalho pedagógico com crianças menores de seis anos. Portanto, as Diretrizes do curso de Pedagogia (2006), em seu artigo $4^{\circ}$, reforçam que,

O curso de Licenciatura em Pedagogia destina-se à formação de professores para exercer funções de magistério na Educação Infantil e nos anos iniciais do Ensino Fundamental, nos cursos de Ensino Médio, na modalidade Normal, de Educação Profissional na área de serviços e apoio escolar e em outras áreas nas quais sejam previstos conhecimentos pedagógicos (BRASIL, 2006, p. 2).

Para exercer a função de docência, esse documento reforça a necessidade de que o licenciando em Pedagogia conheça a realidade escolar, aprofunde-se em teorias e métodos educacionais, para a efetivação de ações que propiciem seu aprofundamento sobre o fenômeno educacional em diferentes níveis. Para Saviani (2010, p. 209), isto pode ser sintetizado da seguinte maneira: “[...] os cursos de formação de professores devem garantir uma sólida cultura que lhes permita atingir uma aguda consciência da realidade em que vão atuar associada a um consistente preparo teórico-científico que os capacite à realização de uma prática pedagógica coerente e eficaz”. Pode-se afirmar, então,

[...] que a profissão docente é uma prática educativa que como tantas outras é uma forma de intervenção na realidade social. Entende-se que esta é uma das atividades de ensino e formação ligadas à prática educativa mais ampla que ocorre na sociedade. Na sua acepção corrente é definida como uma atividade prática. O professor em formação está se preparando para efetivar as tarefas práticas de ser professor. Dado que não se trata de formá-lo como reprodutor de modelos práticos dominantes, mas capaz de desenvolver a atividade material para transformar o mundo natural e social humano (GHEDIN; OLIVEIRA; ALMEIDA, 2015, p. 172).

Diante disso, diferentes estudos destacam que, em muitos cursos de Pedagogia, há questões genéricas e pontuais quanto à formação para docência na Educação Infantil, com disciplinas específicas, o que não permite, em muitos momentos, a articulação teórico-prática necessária (PINHEIRO; ROMANOWSKI, 2010; ROMANOWSKI, 2012).

Neste sentido, é no estágio supervisionado na Educação Infantil que os saberes/conhecimentos, sejam do âmbito disciplinar ou experiencial, acabam sendo mobilizados nas situações de planejamento para o trabalho pedagógico com as crianças. Nesse processo de pensar sobre a realidade educativa, organizar situações de aprendizado e refletir sobre a avaliação e o acompanhamento das crianças, os licenciandos conhecem, de maneira mais objetiva, a especificidade do ser professor de crianças pequenas. Assim,

[...] os alunos precisam conhecer conceitos básicos nas disciplinas que tratam da educação infantil, os quais abordam desde o conceito de criança/infância, aspectos da história da educação infantil, políticas vigentes que orientam as propostas pedagógicas das instituições, bem como conceitos relativos à avaliação e acompanhamento nessa etapa. Todos os elementos citados possuem seus desdobramentos, os quais vão sendo discutidos, refletidos, ao longo

$\overline{{ }^{2} \text { Redação da LDB n }}$ 9.394/1996 alterada pela Lei no 12.796/2013. 
do curso, integrados também a outras disciplinas ligadas ao campo didático/metodológico, histórico/político, entre outras. A área da educação infantil demanda ter a sua relevância desde a formação inicial, para que os(as) futuros(as) professores(as), ao estarem atuando nesta etapa, reconheçam-se como profissionais. Assim, vai-se rompendo com o ciclo e a visão que secundariza o trabalho docente com crianças menores, pois em muitos momentos da história, a ausência de uma formação específica levou muitos profissionais a atentarem apenas às questões de cuidado, e com pouca ou nenhuma remuneração (PIETROBON, 2018, p. 67).

A docência na Educação Infantil possui a sua peculiaridade, haja vista que lida com crianças muito pequenas, e que precisam que as ações de cuidado, educação e brincadeiras estejam relacionadas ao planejamento docente e integradas à rotina institucional. Então, "a formação de profissionais da educação infantil precisa ressaltar a dimensão cultural da vida das crianças e dos adultos com os quais convivem, [...] do mesmo modo a que os adultos concebam a criança como sujeito histórico, social e cultural" (KRAMER, 2005, p. 129).

O cuidado, a educação e as brincadeiras estão em todas as ações na etapa da Educação Infantil, pois mesmo em situações de cuidado, como os momentos de higiene, por exemplo, o professor pode estar tratar de realizá-lo com um viés pedagógico e incluindo a ludicidade. O cuidado com as crianças menores vai além de uma prática assistencialista, de modo que está mais atrelado ao entendimento do que a criança necessita em cada fase, tem relação com acolhê-la, respeitar seu ritmo e estimulá-la nas atividades que são da rotina, mas que podem ser de muito aprendizado. Em outras palavras, cuidar e educar fazem parte da profissionalidade do docente que trabalha na educação infantil (COSTA, 2006).

O brincar constitui a essência da infância e cuidar-educar por meio de brincadeiras é o foco de um planejamento que se dirige às crianças, bem como um direito delas como sujeitos sociais. Para Salomão (2013), por meio do brincar, as crianças socializam-se, compreendem o espaço do outro, trocam experiências e é um rico espaço para que os professores possam observá-las e saber do que elas gostam nesses momentos. Isto pode facilitar a organização de uma prática pedagógica trazendo elementos da brincadeira, que irá despertar na criança mais interesse em participar e desenvolver a atividade.

Diante dessa tríade, a discussão do conceito de criança/infância é um aprendizado e uma reflexão a ser realizada no curso de formação docente, pois desta concepção derivam as epistemologias para o trabalho pedagógico nessa etapa, com as escolhas para as ações do estágio supervisionado em Educação Infantil no curso de Pedagogia. O referido estágio pode ser caracterizado,

[...] como uma atividade de aproximação com o campo profissional, por tratar-se de uma forma de inserção no mundo do trabalho e na área específica de atuação, de possibilidade de conexão entre a teoria estudada e a prática observada nas instituições que acolhem as estagiárias, configurando-se, assim, como um passo importante na construção das identidades profissionais (GOMES, 2009, p. 67).

Para Garanhani (2010), ser docente na Educação Infantil requer dos profissionais que eles se atentem às particularidades das crianças, pois é uma etapa em que elas são muito dependentes. Ainda, a rotina na Educação Infantil exige planejamento e organização do espaço e do tempo diferenciados do Ensino Fundamental, em especial porque o lúdico necessita estar integrado às práticas educativas. Também, o atendimento às crianças por meio da afetividade, do olhar e da atenção são necessários, além da relação mais ampla com a comunidade, pais/responsáveis das crianças, e a troca com os pares para a discussão da proposta pedagógica que se trabalha, para avaliação e revitalização contínuas.

Desta maneira, a formação inicial no curso de Pedagogia torna-se um espaço rico para a promoção de aprendizados acerca do ser docente na Educação Infantil, tendo em vista que podem ser realizadas discussões ancoradas na literatura que possa dar subsídio às análises da prática pedagógica nesta etapa. Assim, a pesquisa torna-se eixo da formação e sua continuidade.

[...] ao refletir sobre a sua própria prática, ao identificar e diagnosticar problemas que nela ocorrem, ao se colocar intencionalmente a possibilidade de intervir em tal situação utilizando metodologias apropriadas, o professor converte-se em investigador da sua própria prática, desenvolve o seu profissionalismo e competência epistemológica (GARCÍA, 1999, p. 183). 
No estágio, especificamente, de acordo Ghedin, Oliveira e Almeida (2015), a pesquisa dá suporte no âmbito da retomada de saberes para a análise de práticas vivenciadas nos diferentes contextos de atuação dos estagiários. Isto requer diferentes olhares por parte dos estagiários, considerando a situação pedagógica, sua postura diante desta e a ancoragem em conhecimentos já internalizados. Nesta perspectiva,

[...] é que se vê a importância da formação inicial, enquanto desencadeadora do perfil profissional. Cabe a ela, portanto, com vistas à profissionalização, propiciar ao professor o desenvolvimento da competência técnica, humana e política, bem como buscar a relação técnica/ ética/política (PAPI, 2005, p. 70).

A formação inicial também é campo de aprendizado de diferentes metodologias de ensino e suas bases teórico-epistemológicas, o que pode resultar em possibilidades de criação de atividades e propostas a partir delas. Além disso, o exercício de analisar a própria prática vivenciada nos estágios supervisionados auxilia o licenciando a aprofundar seus conceitos, mobilizar saberes e conhecimentos, e propor outras ações pedagógicas. Isto porque, [...] "na ação profissional coexistem a ação e o discurso sobre a ação. Sabe-se que os professores podem conseguir ser melhores profissionais refletindo sobre o que fazem" (GARCÍA, 1999, p. 185).

André (2001) pontua que uma das formas que pode articular o ensino e a pesquisa na formação dos professores é de que a pesquisa seja um eixo do curso, perpassando ações da formação inicial e continuada no âmbito institucional, com análises de práticas na escola retratadas em investigações publicadas, com atividades nas disciplinas do curso que possam levar os licenciandos a desenvolver atitudes investigativas, e que estas ações possam ser pensadas coletivamente pelos professores que congregam a formação. De acordo com Ghedin, Oliveira e Almeida (2015, p. 170),

[...] o professor é competente à medida que pesquisa. Ele alia a docência à pesquisa como forma de articular a teoria-prática como forma de expressar sua competência técnica e seu compromisso político com a práxis de professor. [...] Assim, o estágio como estudo, pesquisa e prática pedagógica da atividade docente cotidiana, envolve o exame das determinações sociais mais amplas, bem como da organização do trabalho nas escolas.

Por esse mesmo viés, André (2001) destaca a possibilidade de que os professores retratem suas pesquisas efetivadas e com resultados nas disciplinas que trabalham, o que poderá levar, a partir das discussões, a novas temáticas e projetos de pesquisa. Nesse entendimento, o curso de formação docente tem papel fundamental no desenvolvimento do espírito investigativo do licenciando, no intuito de que, ao observarem as situações da realidade do ensino, possam escolher caminhos e tomar decisões a partir de suas bases teóricas, mas, sobretudo, porque possuem instrumentalização que lhes permite adotar posturas e buscar soluções para situações análogas às vivenciadas na graduação.

Entretanto, convém ressaltar, de acordo com Ghedin, Oliveira e Almeida (2015), a importância do currículo dos cursos de formação docente. Este se constrói a partir da definição coletiva do projeto pedagógico do curso e registram-se os critérios de seleção e organização dos referenciais de conhecimentos, metodologias, atitudes e valores. Com esse entendimento,

[...] o curso há de propor-se, no seu currículo, um trajeto de formação que privilegie a: indissociabilidade entre ensino, pesquisa e extensão; interdisciplinaridade e transdiciplinaridade; formação profissional para a cidadania; autonomia intelectual; responsabilidade, compromisso e solidariedade social (GHEDIN; OLIVEIRA; ALMEIDA, 2015, p. 183).

Portando, é necessário que no currículo se expressem as bases processuais de toda formação, superando a fragmentação do conhecimento ao longo dessas bases, com ações integradas entre o conhecimento preconizado e a prática profissional. Dessa forma,

Se queremos nas escolas professores que refletem sobre as suas práticas (e sobre os propósitos e valores que lhes estão subjacentes), então os cursos de formação (inicial, mas também contínua) têm de ser organizados em função deste propósito, colocando de lado processos e práticas de formação dominados, em grande parte, por modelos tradicionais, escolarizados e baseados numa racionalidade técnica (FLORES, 2003, p. 155). 
Assim, se de fato se busca por meio da educação contribuir para o desenvolvimento de uma sociedade mais justa e igualitária, urge questionar a tradição formativa de caráter transmissor, com a predominância de teorias descontextualizadas, indiferentes aos problemas do cotidiano docente.

\section{ROTEIRO DIDÁTICO PARA A PLANEJAMENTO DA PRÁTICA PEDAGóGICA NA EDUCAÇ̃̃o INFANTIL}

No intuito de contextualizar, o roteiro didático de Pietrobon (2018) é oriundo de uma pesquisa com egressos de um curso de Pedagogia na modalidade a distância - EaD de uma instituição pública de Ensino Superior do Paraná. Na referida pesquisa, buscou-se realizar um levantamento dos aportes teóricos e metodológicos desse curso em relação à área da Educação Infantil, com uma amostra de 137 egressos, o que deu base para a elaboração de um produto educacional.

Esse levantamento para a elaboração do roteiro didático em questão ocorreu por meio de questionário enviado pelo Google Docs, e teve a devolutiva final de 51 participantes (37,22\%), após muitas tentativas de contato por e-mail e telefonemas. O questionário abordou questões relacionadas ao perfil dos egressos, o curso de Pedagogia EaD, as disciplinas com enfoque na Educação Infantil e a prática pedagógica nesta etapa. Esses egressos pertenciam a seis polos de funcionamento do curso no Paraná, nos munícipios de Prudentópolis, Lapa, Apucarana, Pato Branco, Laranjeiras do Sul e Dois Vizinhos 3 .

Os dados que emergiram desse processo demonstraram que, embora o curso de Pedagogia EaD investigado tenha atendido às expectativas em termos formativos dos egressos, deixou algumas lacunas. Entre elas citam-se questões didático-pedagógicas voltadas à prática docente na Educação Infantil e a necessidade de atendimento mais próximo nos estágios desta etapa educacional. Considera-se que o planejamento para o referido estágio exige uma amplitude de saberes e conhecimentos, bem como a articulação com a realidade da instituição na qual se realizam suas ações. Desse modo,

[...] percebeu-se que as disciplinas específicas da área da educação infantil necessitam de uma continuidade, ou articulação com outras disciplinas do curso, para que a formação não seja limitadora, caso contrário, ocorre uma ruptura entre os fundamentos trabalhados, geralmente no primeiro ano, e o estágio supervisionado no terceiro ano do curso (PIETROBON, 2018, p. 185).

Outro indicador, com 18\% das respostas dos egressos, foi em relação à falta de interação em algumas disciplinas e na organização do estágio supervisionado, em especial quanto à estruturação do planejamento e relatório final. Então, pontuou-se que este dado traz uma realidade a ser pensada em cursos de Pedagogia EaD quanto ao uso e ampliação de ferramentas, bem como de momentos presenciais para a organização dos estágios supervisionados para seu acompanhamento. Isto tendo em conta que esses cursos abrangem um número maior de alunos, os quais trazem inúmeras demandas da prática realizada nas escolas dos municípios que abrangem os polos de funcionamento dos cursos.

A partir desses aspectos da pesquisa, buscou-se atender a uma prerrogativa do Programa de Pósgraduação em Ensino de Ciência e Tecnologia (UTFPR), que exige um produto educacional vinculado à tese. Neste caso, organizou-se um roteiro didático para o planejamento na etapa da Educação Infantil ${ }^{4}$, voltado ao estágio supervisionado em cursos de Pedagogia EaD.

Em termos teóricos que deram base à construção do roteiro didático, optou-se pela epistemologia interacionista (BECKER, 2012; 2008), na qual se destaca o papel da interação entre professor e crianças, sem que o professor esteja em uma posição de mando, mas que dialoga, estimula, interage com elas em um contexto mais amplo, de forma que este é considerado na construção do conhecimento.

\footnotetext{
${ }^{3}$ Dados obtidos na pesquisa de doutorado de Pietrobon (2018), intitulada A formação do professor da educação infantil no contexto da modalidade a distância: o curso de Pedagogia em foco, defendida no Programa de Pós-graduação em Ensino de Ciência e Tecnologia, da Universidade Tecnológica Federal do Paraná.

${ }^{4} \mathrm{O}$ roteiro didático passou por um processo de validação por professores da Educação Infantil, 26 ao todo, em curso de formação continuada, também por especialistas, 4 doutores em Educação, os quais possuem publicações na área da infância, atuam em cursos de Pedagogia e têm experiência com a modalidade a distância.
} 
Nesta vertente, o conhecimento sistematizado é valorizado, mas há espaço para que os saberes das crianças possam ser incluídos e relacionados aos temas explorados em situações problematizadoras. Assim,

Nega-se, portanto, o autoritarismo do professor e o autoritarismo do aluno, simultaneamente. Trata-se de um modelo pedagógico que, ao contrário do que muitos pensam, resgata a importância dos polos da relação pedagógica escolar, fazendo-os crescer a níveis inéditos. Este modelo, traduzido em prática, busca a destruição dos fatores que prejudicam ou até anulam os polos da relação, e o resgate da dinâmica própria do conhecimento que vislumbrar um crescimento possível [...]. O suporte deste modelo encontra-se na psicologia genética de Piaget, na obra pedagógica de Paulo Freire, em pedagogias de fundamentação marxista: na psicologia do desenvolvimento de Vygotsky, em Gramsci, Wallon, etc. Sua fundamentação epistemológica encontra-se no interacionismo de tipo construtivista (BECKER, 2012, p. 12, grifo do autor).

Além da epistemologia interacionista, a abordagem interdisciplinar é parte da perspectiva de abordagem dos temas/conteúdos nesse roteiro para a Educação Infantil. Para Fazenda (2008), é possível a interação entre as áreas de conhecimento, mas que a troca aconteça criando possibilidades de incrementar e ampliar o prisma de visão quanto ao que se está trabalhando com as crianças, não fragmentando o conhecimento ou simplificando-o (MORIN, 2006). Fazenda (2008) destaca que, para desenvolver um trabalho interdisciplinar é necessária uma postura diferenciada por parte do docente, que este possa interatuar, relacionar diferentes temas e saberes, mas respeitando o contorno das áreas de conhecimento.

Então, para o planejamento na etapa da Educação Infantil, em especial nas práticas de estágio supervisionado em Educação Infantil nos cursos de Pedagogia EaD, elaborou-se um roteiro com sete momentos didáticos, os quais possuem itens que são necessários de serem contemplados para a organização da prática pedagógica com as crianças. Esse roteiro didático teve a premissa de que o ponto de partida é conhecer as crianças e seu contexto. Para tanto, inicia com o desenvolvimento do conceito de criança que o estagiário/licenciando possui, mas sempre relacionando ao contexto de atuação, ou seja, a proposta da instituição e suas bases teórico-epistemológicas.

Tomando como base o conceito de crianças e o conhecimento da realidade institucional é que se estruturam os temas/conceitos em um viés interdisciplinar, de modo a desenvolver as atividades e propostas dando voz às crianças, interagindo com elas e com a organização de atividades que possam indicar seu progresso. Haja vista, a necessidade de acompanhamento das crianças sem fins de promoção. Então, tendo estes conceitos iniciais, pensou-se no roteiro didático que segue:

Momento didático 1 - Explicitar o conceito de criança que o professor possui, ao qual se recomenda estar em consonância com o projeto político pedagógico da instituição. Deixar claro o viés teórico que embasará as práticas pedagógicas a serem desenvolvidas.

Momento didático 2 - Temas e/ou conteúdos a serem desenvolvidos (definidos pela instituição que abriga o estágio supervisionado).

Momento didático 3 - Objetivos que se pretende alcançar.

Momento didático 4 - Áreas do conhecimento nas quais o tema pode ser contextualizado.

Momento didático 5 - Práticas pedagógicas e suas etapas de desenvolvimento (atividades, propostas). Tempo de duração das atividades, conforme a rotina da instituição (integral/parcial).

Momento didático 6 - Recursos implicados no decorrer das práticas pedagógicas (Materiais diversos, pessoas envolvidas, espaço a ser utilizado).

Momento didático 7 - Avaliação do processo - além da avaliação do desenvolvimento e participação das crianças, também preconiza a autoavaliação do(a) estagiário(a). É necessário que o(a) mesmo(a) realize anotações, ao final de cada dia, das impressões das crianças frente às atividades desenvolvidas, para que o professor regente possa ter essa análise também. Além disso, anotar em diário de classe as dificuldades, conquistas, ações planejadas e não concretizadas, mudanças de atividades, entre outros aspectos que se fizerem necessários.

Referências utilizadas: Livros didáticos e/ou de literatura infanto-juvenil, apostilas, consulta a sites especializados/blogs, jornais, revistas, periódicos, entre outros (PIETROBON, 2018, p. 181-182). 
Este roteiro didático foi pensado para cursos de Pedagogia EaD, tendo o conhecimento de que as realidades dos polos de atendimento dos cursos são muito diversas e cada município pode ter uma perspectiva diferenciada em termos de atendimento às crianças na etapa da Educação Infantil, embora devam atender parâmetros e legislação nacionais. Destarte, um roteiro didático mais flexível e com viés teórico mais amplo poderia atender estas peculiaridades que se apresentam nos processos de formação inicial docente. Contudo, esse roteiro didático também pode ser desenvolvido em cursos de Pedagogia presencial, o que se explicita no item seguinte, com uma experiência realizada neste ano de 2019, no estágio supervisionado em Educação Infantil, em uma instituição pública de Ensino Superior paranaense.

\section{AS ETAPAS DO ESTÁGIO SUPERVISIONADO NA EDUCAÇÃO INFANTIL}

O curso de Pedagogia da Universidade Estadual do Centro-Oeste (UNICENTRO), campus Universitário de Irati, foi criado em 1975 e reconhecido pelo Decreto Federal n ${ }^{\circ} .82828$ de 11 de dezembro de 1978, publicado no Diário Oficial 19916 de 12 de dezembro de 1978. No município de Prudentópolis, o curso no qual foi realizada a pesquisa para este estudo, foi autorizado no ano 2000 pelo Decreto 2.299.

Desde a criação do curso, seus objetivos principais e a estrutura curricular passaram por alterações decorrentes de mudanças e influências políticas no cenário nacional e internacional. Atualmente 5 , o Projeto Pedagógico Curricular (PPC) que estrutura o Curso de Pedagogia foi elaborado com base nas Diretrizes Curriculares Nacionais Resolução CNE/CP nº 01 de 15/5/2006.

Conforme o PPC, a concepção do professor pesquisador, considerando a tríade ação-reflexão-ação, ampara a formação dos pedagogos e o curso busca oportunizar aos acadêmicos sólida formação por meio da articulação entre os fundamentos da educação, as metodologias e práticas de ensino e as políticas educacionais. Há preocupação com a relação dialética entre teoria-prática e com o conhecimento da real situação da educação no contexto sócio, político, econômico e cultural, considerando as relações macro e micropolíticas.

Com tal intencionalidade, o curso visualiza uma formação acadêmica que desenvolva a autonomia do professor, enquanto sujeito de sua atuação profissional e pessoal, capaz de integrar teoria e prática superando a dicotomia entre conhecimentos específicos e pedagógicos, através da prática da pesquisa.

Nesse sentido, o estágio supervisionado compõe o currículo do curso presencial de Pedagogia e é entendido como um espaço interdisciplinar com clara definição da responsabilidade para o exercício profissional do educador. Tem como finalidade proporcionar o conhecimento da realidade educativa contemplando o estudo, a análise e a reflexão, com proposição de ações para o processo ensino-aprendizagem, bem como elaboração, execução e avaliação de projetos e programas educativos, não apenas nas salas de aula, mas também na escola e demais ambientes sociais voltados à educação e ao ensino.

Portanto, no estágio, os acadêmicos irão vivenciar experiências do exercício profissional que ampliem e fortaleçam atitudes éticas e conhecimentos científicos, pedagógicos e técnicos em contato direto com turmas de Educação Infantil, Anos Iniciais do Ensino Fundamental, disciplinas pedagógicas do Ensino Médio na Modalidade Normal e em Cursos de Educação Profissional, e na Gestão Escolar. Sobre o Estágio Supervisionado na Educação Infantil ${ }^{6}$,

Há muito o que se debater e a se produzir sobre o estágio na formação do futuro pedagogo, visto que este atuará de forma complexa na educação infantil, tanto na docência quanto na gestão escolar. O exercício de leitura de pesquisas na área e suas compreensões são de extrema necessidade, tal como se aproximar das instituições de Educação Infantil com o olhar observador e refletir a partir disso. A discussão teórica e prática não se finda neste momento, pois se espera que, a partir deste olhar observador, novos conhecimentos e debates sejam produzidos pelos alunos - futuros professores/pedagogos (PINEDA, 2015, p. 76).

\footnotetext{
${ }^{5}$ Até o final do ano de 2019. Em 2020 entrará em vigência o novo Projeto Pedagógico Curricular (PPC) elaborado com base nas Diretrizes Curriculares Nacionais Resolução CNE/CP 02/2015, aprovado pelo Conselho Pleno do Conselho Nacional de Educação (CNE) em 9 de junho de 2015, e homologado pelo MEC em 24 de junho de 2015.

${ }^{6} \mathrm{O}$ estágio supervisionado em Educação Infantil e Anos Iniciais do Ensino Fundamental é realizado no $3^{\circ}$ ano do curso de graduação em Pedagogia.
} 
Em relação à carga horária do estágio de docência ${ }^{7}$ na Educação Infantil, são 68h de disciplina teórica, além das atividades práticas de imersão nos Centros Municipais de Educação Infantil e Escolas, que são 20h de observação, 20h de participação e 20h de atuação. Além destas, por fim, 15h para construção dos relatórios, avaliações, análise crítica e reflexiva sobre o trabalho desenvolvido e apresentação em seminário final.

Na etapa da observação e da participação buscam-se definir, com os acadêmicos, algumas questões que auxiliam no direcionamento do olhar para o campo e sistematização de escrita e reflexão desses momentos. Para o planejamento da etapa de atuação, no ano de 2019, optou-se pelo roteiro didático (PIETROBON, 2018) composto pelos 7 (sete) momentos didáticos como forma de organizar a prática pedagógica.

A escolha desse roteiro para o planejamento ocorreu em virtude do mesmo apresentar-se como recurso favorável e instrutivo à organização do trabalho pedagógico em um viés interdisciplinar para a articulação entre as áreas de conhecimento. Dessa maneira, [...] "pode-se possibilitar aos temas pertinentes ao trabalho pedagógico com crianças na etapa da educação infantil, que sejam abordados de maneira não fragmentada, interatuando" [...] (PIETROBON, 2018, p. 139).

Destaca-se, ainda, que o roteiro didático elaborado por Pietrobon (2018) trata-se de um roteiro de planejamento para a efetivação do Estágio Supervisionado na Educação Infantil para cursos de Pedagogia na modalidade a distância. Entretanto, reitera-se

[...] que os momentos didáticos poderão ser desenvolvidos, da mesma maneira, por cursos de Pedagogia na modalidade presencial, haja vista que as Diretrizes Curriculares, os princípios e o foco formativo são os mesmos em ambas as modalidades. O que difere neste caso é a mediação professor(a)-aluno-conhecimento (PIETROBON, 2018, p. 155).

Isto posto, o roteiro de planejamento é um instrumento que pode ser trabalhado com egressos (formação continuada) e acadêmicos (formação inicial) do curso de Pedagogia, tanto da modalidade a distância como da modalidade presencial.

Por fim, com relação à formação inicial, ao final de cada estágio espera-se que os futuros docentes, no movimento de análise e reflexão, consigam se apropriar de diferentes conhecimentos que possam revigorar e engendrar novas práticas.

\section{ANÁLISE DO ROTEIRO DIDÁTICO IMPLEMENTADO NA ETAPA DE ATUAÇÃO DO ESTÁGIO SUPERVISIONADO EM EDUCAÇ̃̃O INFANTIL}

Para análise do roteiro didático (PIETROBON, 2018) utilizado na etapa de atuação do estágio supervisionado em Educação Infantil no curso de Pedagogia, ao final do primeiro semestre de 2019, solicitou-se que as acadêmicas respondessem um questionário com 3 (três) perguntas: 1 - O roteiro de planejamento, com momentos didáticos, contribui para a elaboração do planejamento da Educação Infantil? De que forma? 2 - Sentiu dificuldades em elaborar o planejamento para atuação, tendo como base o roteiro didático utilizado? 3 - Gostaria de sugerir algum aspecto a ser acrescentado ou modificado no roteiro didático (PIETROBON, 2018), considerando a prática pedagógica vivenciada no estágio supervisionado na Educação Infantil?

Estas questões foram respondidas por 22 (vinte e duas) acadêmicas do $3^{\circ}$ (terceiro) ano do curso de graduação em Pedagogia de uma instituição de ensino superior (IES) pública, cujas idades variavam entre 19 e 42 anos, sendo que a maioria já atuava no campo da Educação Infantil por meio do estágio remunerado não obrigatório ${ }^{8}$.

\footnotetext{
${ }^{7}$ Para o estágio nos Anos Iniciais do Ensino Fundamental e nas Matérias Pedagógicas do Ensino Médio, a dinâmica da carga horária permanece como no Estágio em Educação Infantil. Já para o Estágio em Gestão Educacional amplia-se a carga horária de atuação e para construção do relatório final.

${ }^{8}$ É o estágio desenvolvido como atividade opcional, acrescida à carga horária regular e obrigatória, e parte do projeto pedagógico do curso.
} 
Para investigação das respostas buscou-se respaldo em Bardin (2011), a partir da proposta de Análise de Conteúdo. Em uma abordagem qualitativa, a Análise de Conteúdo organiza-se em três fases cronológicas: a pré-análise; a exploração do material; e o tratamento dos resultados, permitindo a inferência e a interpretação. Após a pré-análise e a exploração dos dados, para análise efetivamente, definem-se categorias, que são compreendidas como grupos, classes ou temáticas que agregam determinados elementos com características comuns.

Em vista disso, após a leitura das respostas, para garantir a não exposição de cada participante, optou-se pela codificação A1; A2; A3..., e assim sucessivamente, até a A22, organizando as respostas em 3 (três) categorias: organização do planejamento; dificuldade e/ou facilidade na elaboração do planejamento; e, alterações quanto a estrutura do roteiro.

\section{ORGANIZAÇÃO DO PLANEJAMENTO}

“É uma forma mais organizada de planejamento, diferente dos outros planos” (A1).

“O roteiro traz etapas, e isso auxilia na elaboração, também favorece a organização da escrita de maneira prática e fácil” (A5).

“O planejamento ficou mais fácil pelo fato de obter explicações em cada momento. Fica um plano de aula mais didático" (A6).

"Esse modelo de planejamento é mais completo e amplia nossos conhecimentos na hora da elaboração dos mesmos” (A9).

"O planejamento ficou mais organizado e coerente, com os momentos didáticos. E de acordo com o planejamento, tivemos mais facilidade para desenvolver o estágio" (A11).

"Ele tem uma forma organizada dos momentos, facilitando o raciocínio para sua elaboração" (A16).

"É um modelo mais prático. Mais fácil de organizar" (A16).

"Foi nosso primeiro estágio, primeiro contato com plano de aula, foi bom, ajudou bastante" (A18).

“O roteiro de planejamento com momentos didáticos contribui para o planejamento, pois ele possibilita uma melhor organização dos dados e das atividades, o que também levou a uma reflexão das práticas pedagógicas” (A19).

"Através dos momentos didáticos pude obter uma melhor organização no meu plano de aula" (A21).

Sobre a primeira questão, verificou-se que todas as respostas destacaram que o roteiro de planejamento (PIETROBON, 2018) possibilitou melhor organização das práticas pedagógicas. Assim, é um instrumento que favorece a organização, sistematização e direcionamento das decisões sobre a ação a ser realizada.

Sobre as ações docentes, Franco (2012) considera que o professor, ao planejar sua prática pedagógica traçando caminhos para o que irá fazer, por que irá fazer e como deverá fazer, vai se afastando do laissez-faire pedagógico e incorporando vida à escola. "[...] Vida é dinamismo, dialética, contradição e tensão" (FRANCO, 2012, p. 168).

Nesse movimento de direção de sentido, as práticas pedagógicas precisam ser organizadas, criadas e recriadas buscando direções emancipatórias, críticas e inclusivas. Isto posto, Vasconcellos (1999, p. 75) destaca que o [...] "planejamento não é uma coisa que se coloca como um 'a mais' no trabalho do professor: muito pelo contrário, é o próprio eixo de organização e definição deste trabalho”. Portanto, é a partir de um planejamento, com viés reflexivo e que seja flexível, que o docente realiza sua ação, a qual pode ser revista, melhorada e revisitada. 


\title{
DIFICULDADE E/OU FACILIDADE NA ELABORAÇ̃̃O DO PLANEJAMENTO
}

\author{
"No momento didático 1 que senti dificuldade em relacionar o conceito de criança com as \\ atividades propostas" (A2). \\ "No início foi um pouco difícil, porém com as explicações esse roteiro possibilitou organizar \\ melhor as atividades e isso se tornou mais fácil” (A7). \\ "Um pouco, no momento 1, para relacionar e se basear em algum autor, mas, no fim foi bom, \\ pois é preciso ter um autor base” (A10). \\ "Não, pois seguimos o roteiro, foi fácil elaborar o planejamento" (A11). \\ "Não, pois estava bem explicado" (A14). \\ "Não. Ele se apresenta de forma bem explícita” (A16). \\ "Não senti dificuldade, pois o roteiro nos ajudou e auxiliou para planejar" (A18). \\ "Encontrei dificuldade em relacionar a teoria do autor com as atividades que seriam desen- \\ volvidas” (A20). \\ "Não senti muita dificuldade, o roteiro estava bem organizado com os momentos e ajudou \\ para escrever as atividades, metodologia e recursos" (A22).
}

Nas respostas, verificou-se que 13 (treze), do total de 22 (vinte e duas) acadêmicas, sentiram um pouco de dificuldade na organização do planejamento, referente à definição do momento didático 1 , o qual exige um conceito de criança, para que nos próximos momentos desmembrem-se os objetivos, atividades e avaliação coerentes com o conceito. Esclarecemos que, no roteiro didático empregado, não há uma concepção de criança/infância rígida ou prescritiva, mas uma indicação de que se apresentem teorias em uma epistemologia interacionista, o que deixa flexível para que os acadêmicos possam adequar às concepções presentes nas propostas pedagógicas das instituições de ensino, nas quais se realizam os estágios supervisionados.

Entende-se, então, que o roteiro didático provoca a reflexão de que a teoria baliza as práticas. Isto é importante e necessário, pois a ausência de fundamentos pedagógicos capazes de tecer práticas educativas, de acordo com Franco (2012), provoca práticas engessadas, escolas mortas, sem alma, atividades sem sentido e sem criatividade.

Vê-se, então, que os professores precisam revisitar suas concepções teóricas que orientem com clareza suas práticas pedagógicas, considerando que [...] “teorizar é iluminar a ação, é decifrá-la, é apreender o movimento do real, portanto, algo por essência relacionado à prática” (VASCONCELLOS, 1999, p. 44).

Para Pineda (2015, p. 74), a pesquisa é um elemento articulador nesse sentido, que dinamiza o acadêmico à investigação, na prática do estágio in loco, ou anteriormente no planejamento, e isto poderá levá-lo a "[...] não se render às imposições limitadas da escola, mas sim de ser reflexivo-crítico da sua prática independente do sistema”. Desse ponto de vista, Vaillant e Marcelo (2012), ao discutirem o desenvolvimento profissional dos professores, ressaltam que, ao longo de sua carreira, eles necessitam ter uma atitude de indagação da realidade, formulando questionamentos sobre ela e buscando possibilidades de resolução das problemáticas.

\section{ALTERAÇÕES QUANTO A ESTRUTURA DO ROTEIRO}

Com relação a sugerir algum aspecto a ser acrescentado ou modificado no roteiro didático, as respostas foram unânimes e objetivas de que não há o que acrescentar ou alterar, conforme as 22 acadêmicas. Inserimos algumas respostas para exemplificar:

\footnotetext{
“Não. O roteiro está bem elaborado e completo, não há necessidade de alteração” (A5).

“Não. O modelo apresentado já é bem completo” (A7).

“No meu ponto de vista não, porque consegui me organizar bem” (A21).

"No momento não tenho sugestões a acrescentar" (A22).
} 
Entende-se, dessa forma, que a proposta do roteiro didático para o planejamento contempla os elementos essenciais que precisam ser pensados para organização das práticas pedagógicas no estágio supervisionado em Educação Infantil, em cursos de Pedagogia presencial, conforme o olhar das acadêmicas investigadas.

\section{CONSIDERACÕ̃ES FINAIS}

A formação docente é campo de estudo, reflexões, análises, trocas de experiências e realização. Enquanto espaço formativo para o professor da Educação Infantil, engloba o trabalho no campo disciplinar dos conceitos de criança/infância, metodologias diferenciadas, vertentes teóricas, avaliação e acompanhamento das crianças, bem como a forma de integração de todos estes saberes na ação docente que, no caso, ocorrem na efetivação do estágio supervisionado na Educação Infantil.

Na proposta inicial deste trabalho, teve-se como objetivo realizar um levantamento com acadêmicas de um curso de Pedagogia de uma IES pública, na modalidade presencial, as quais utilizaram o roteiro didático de Pietrobon (2018) para a organização da prática pedagógica. O referido roteiro foi elaborado para a finalidade de ser utilizado no estágio supervisionado em Educação Infantil, ancorado em uma epistemologia interacionista, com viés interdisciplinar para a abordagem das temáticas que compõem o currículo da primeira etapa da Educação Básica.

A análise das acadêmicas demonstrou que o roteiro didático, após ser utilizado na organização das 20h de atuação, deu suporte ao planejamento das práticas, auxiliando-as a pensarem em cada elemento necessário para a docência.

Portanto, ao realizarem o planejamento com o roteiro didático (PIETROBON, 2018), as acadêmicas destacaram a possibilidade de melhor organização das atividades pedagógicas, haja vista que já haviam vivenciado experiências de planejamento em outros momentos da formação. Observou-se maior clareza e facilidade no registro dos conteúdos, objetivos, metodologia, avaliação, entre outros.

Verificou-se, ainda, que o roteiro didático impulsiona a reflexão de concepções teóricas para nortear a prática docente. Com isto, primeiramente, percebeu-se que gerou certa insegurança nas acadêmicas, mas no decorrer das reflexões houve a compreensão da relação e da necessidade da transposição e articulação teórico-prática.

Este é um ponto interessante para (re) pensar as possíveis lacunas que podem surgir (e surgem) na formação dos acadêmicos. Este dado pode ser discutido (ou ao menos refletido) pelos professores das IES, sobre as formas dos seus saberes-fazeres que possibilitam (ou não) que os acadêmicos compreendam a indissociabilidade teoria-prática.

Por fim, aponta-se que o roteiro didático contempla todos os eixos necessários e essenciais para que o professor possa elaborar, com coerência e sensatez, o planejamento das atividades pedagógicas com as crianças pequenas, priorizando sempre a tríade cuidar, brincar e educar.

Assim, almeja-se o desenvolvimento integral das crianças, e um dos aspectos a ser considerado é o planejamento do que será propiciado para a interação desses pequenos. Para tanto, destaca-se a importância do processo formativo do estágio e, no ano de 2019, da escolha assertiva do roteiro didático de planejamento da prática pedagógica na Educação Infantil.

\section{REFERÊNCIAS}

ANDRÉ, M. Pesquisa, formação e prática docente. In: ANDRÉ, M. (org.). O papel da pesquisa na formação e na prática dos professores. Campinas, SP: Papirus, 2001.

Bardin, L. Análise de conteúdo. São Paulo: Edições 70, 2011.

BECKER, F. Aprendizagem - concepções contraditórias. Schème - Revista Eletrônica de Psicologia e Epistemologia Genéticas. Volume I nº 1, p. 53-73, Jan/Jun, 2008. 
BECKER, F. A epistemologia do professor: o cotidiano da escola. 15ª ed. Petrópolis, RJ: Vozes, 2012. BRASIL. Lei $\mathbf{n}^{0}$ 12.796, de 04 de abril de 2013. Altera a Lei $\mathrm{n}^{\circ}$ 9.394, de 20 de dezembro de 1996, que estabelece as diretrizes e bases da educação nacional, para dispor sobre a formação dos profissionais da educação e dar outras providências. Disponível em: http://www.planalto.gov.br/Ccivil_03/_Ato20112014/2013/Lei/L12796.htm. Acesso em: 03 de jun. de 2019.

BRASIL. Resolução $\mathbf{n}^{\mathbf{0}}$ 1, de 15 de maio de 2006. Diretrizes Curriculares Nacionais para o curso de graduação em Pedagogia, licenciatura. CNE, 2006.

COSTA, F. N. do A. O cuidar e o educar na educação infantil. In: ANGOTTI, M. (Org.). Educação infantil: para quê, para quem e por quê? Campinas, SP: Editora Alínea, 2006.

FAZENDA, I. C. A. Interdisciplinaridade-transdisciplinaridade: Visões culturais e epistemológicas. In: FAZENDA, I. C. A. (org.). O que é Interdisciplinaridade? São Paulo: Cortez, 2008.

FRANCO, M. A. S. Pedagogia e prática docente. São Paulo: Cortez, 2012.

FLORES, M. A. Dilemas e desafios na formação de professores. In: MORAES, M. C.; PACHECO, J. A.; EVANGELISTA, M. O. (Orgs.). Formação de professores: perspectivas educacionais e curriculares. Porto: Porto Editora, 2003.

GARANHANI, M. C. A docência na educação infantil. In: SOUZA, G. de. Educar na infância: perspectivas histórico-sociais. São Paulo: Contexto, 2010.

GARCÍA, C. M. Formação de professores para uma mudança educativa. Portugal: Porto Editora, 1999.

GHEDIN, E.; OLIVEIRA, E. S. de; ALMEIDA, W. A. de A. Estágio com pesquisa. São Paulo: Cortez, 2015.

GOMES, M. de O. Formação de professores na Educação Infantil. São Paulo: Cortez, 2009.

MORIN, E. Introdução ao Pensamento Complexo. $1^{\text {a }}$ reimp. Porto Alegre: Sulina, 2006.

PAPI, S. de O. G. Professores: formação e profissionalização. Araraquara, SP: Junqueira \& Marin, 2005.

PIETROBON, S. R. G. A formação do professor da educação infantil no contexto da modalidade a

distância: o curso de Pedagogia em foco. 223 f. Tese (Doutorado em Ensino de Ciência e Tecnologia) Programa de Pós-Graduação em Ensino de Ciência e Tecnologia. Universidade Tecnológica Federal do Paraná, Ponta Grossa, 2018.

PINEDA, T. F. G. Estágio em Educação Infantil na formação do pedagogo. In: VERCELLI, L. de C. A.; STANGHERLIM, R. (orgs.). Formação de professores e práticas pedagógicas na Educação Infantil. Jundiaí: Paco Editorial, 2015.

PINHEIRO, G. C. G.; ROMANOWSKI, J. P. Curso de Pedagogia: Formação do professor da educação infantil e dos anos iniciais do ensino fundamental. Form. Doc., Belo Horizonte, v. 02, n. 03, p. 136-151, ago./dez. 2010.

ROMANOWSKI, J. P. Formação inicial de professores: implicações com a educação básica. In: REBOLO, F.; TEIXEIRA, L. R. M.; PERRELLI, M. A. de S. (orgs.). Docência em questão: discutindo trabalho e formação. Campinas, SP: Mercado de Letras, 2012.

SALOMÃO, C. A. R. O brincar e a socialização da criança. In: MORAL, E.; VILHENA, S. P.; PINEDA, T. (Orgs.). Educação infantil na formação do pedagogo. Jundiaí: Paco Editorial, 2013.

SAVIANI, D. Formação de professores. In: SAVIANI, D. Interlocuções pedagógicas: conversa com Paulo Freire e Adriano Nogueira e 30 entrevistas sobre educação. Campinas, SP: Autores Associados, 2010.

VAILLANT, D.; MARCELO, C. Ensinando a ensinar: as quatro etapas de uma aprendizagem. Curitiba: Ed. UTFPR, 2012.

VASCONCELLOS, C. Planejamento: projeto de Ensino-aprendizagem e projeto político pedagógico elementos metodológicos para elaboração e realização. São Paulo: Libertad, 1999. 